\title{
A Desqualificação Social da classe média em Portugal: Uma abordagem qualitativa
}

\author{
Catarina Vieira da Silva ${ }^{1}$ e Francisco Branco ${ }^{2}$ \\ ${ }^{1}$ Faculdade de Filosofia e Ciências Sociais Universidade Católica Portuguesa - Portugal | \\ crsilva@ucp.pt | https://orcid.org/0000-0002-0915-4714 \\ ${ }^{2}$ Faculdade de Ciências Humanas Universidade Católica Portuguesa - Portugal | \\ fnbranco@fch.lisboa.ucp.pt | https://orcid.org/0000-0003-0075-792X
}

\begin{abstract}
Resumo: A presente investigação, tem como objeto central da pesquisa, analisar as principais dinâmicas de vulnerabilização que afetam a classe média, procurando-se compreender designadamente as dimensões relacionadas com a crise económica, quebra de rendimentos, processos de desagregação e rutura familiar, desqualificação social e sofrimento social. Este trabalho baseou-se, como um dos principais eixos teóricos de pesquisa, no ensaio de Serge Paugam sobre a nova pobreza. Partindo deste conceito como representação e categoria analítica, elaborou-se uma proposta de releitura do conceito de desqualificação social perante os desafios da classe média face à crise económica contemporânea. A pesquisa adotou uma estratégia de cariz qualitativo, com base em entrevistas a cidadãos de classe média que experienciaram no presente e passado recentes processos de desqualificação social, tendo sido reunido um corpus de vinte entrevistas com base no princípio da máxima heterogeneidade. No que se refere à codificação e categorização utilizou-se o software MAXQDA para a análise de dados qualitativos.Os dados recolhidos indiciam que estamos perante cidadãos que se afastam dos atributos apontados pela literatura à classe média, em consequência das trajetórias de mobilidade social descendente ou mobilidade ascensional estagnada provocadas pelos processos de vulnerabilização económica e social a que foram submetidos. Esta investigação permitiu ainda concluir que todos os entrevistados sofreram processos de mobilidade social descendente ou exposição a dinâmicas de mobilidade ascensional estagnada, evidenciando-se que uma grande parte dos cidadãos não recorre aos serviços de apoio e ação social, mobilizando preferencialmente as redes de apoio e solidariedade familiar
\end{abstract}

Palavras-chave: Classe Média; Públicos Diferenciados; Desqualificação Social; Serviço Social; Abordagem qualitativa; QDA ${ }^{1}$.

\section{The Social Disqualification of the Middle Class in Portugal: A Qualitive Approach}

\begin{abstract}
The present investigation, has the purpose to analyze the vulnerabilities that affect middle class families, pursuing the comprehension of the dimensions related to economical crisis, income and family breakdown, social disqualification and social suffering. This work was based, as one of the main theoretical axes of research, in Serge Paugam's essay on the new poverty. Based on this concept as representation and analytical category, a proposal was made to re-read the concept of social disqualification faced to the challenges of the middle class in the face of the contemporary economic crisis. This empirical research adopts a qualitative approach and is based on twenty interviews of middle-class citizens who experience or experienced social disqualification. The interviews have the principle of maximum heterogeneity. To apply coding and categorization, it was used MAXQDA software for the analysis of qualitative data. This research suggests we are facing citizens who deviate from the attributes pointed out by the literature to the middle class, as a result of the trajectories of downward social mobility or stagnant upward mobility caused by the processes of economic and social vulnerability to which they were subjected.All the interviewees suffered from processes of downward social mobility or dynamics of stagnant ascensional mobility, and that a large part of the citizens do not seek for social services, mobilizing support networks and family solidarity instead.
\end{abstract}

Keywords: Middle-Class; Differentiated Publics; Social Disqualification; Social Work; Qualitative approach; QDA.

\footnotetext{
${ }^{1}$ Qualitative Data Analysis
} 


\section{Introdução}

A presente investigação visa contribuir para a compreensão dos processos de vulnerabilização económica e social da classe média no contexto português, tomando como observatório a procura do serviço social e de estruturas de apoio e suporte social por este "novo e diferenciado público".

Com esta investigação pretende-se produzir conhecimento relevante sobre as principais dinâmicas de vulnerabilização que afetam a classe média, procurando-se compreender designadamente as dimensões relacionadas com a quebra de rendimentos (e.g. desemprego e precarização laboral), (sobre)-endividamento, processos de desagregação familiar(e.g. divórcios, desqualificação das práticas parentais) e processos de desqualificação social (e.g. exclusão social, estigma).

Assim, sustenta-se que a presente investigação possa ser um contributo para o desenvolvimento de estudos sobre a pobreza contemporânea, bem como o conhecimento dos novos públicos que de forma crescente recorrem ao serviço social. Neste sentido, consideramos necessário o conhecimento das principais dinâmicas de vulnerabilização que afetam a classe média tendo igualmente em vista subsidiar o estudo e adoção de medidas de política pública e social que possam responder de forma mais adequados à natureza dos processos de desqualificação social que afetam estes cidadãos.

O presente trabalho é suportado pela conceptualização de Desqualificação Social de Paugam (1991/2003), que teve como referência a experiência europeia do final da década de 80 associada à degradação do mercado de trabalho, empregos instáveis, desemprego e enfraquecimento dos laços sociais. Face à conjuntura económica e social atual, ensaiouse uma transferência e adaptação conceptual desta categoria para o atual contexto social e novos públicos.

A investigação empírica teve por base vinte entrevistas a cidadãos de classe média experimentando no presente e passado recente, processos de vulnerabilização económica e social e desqualificação social. Com efeito, adotou-se uma estratégia de cariz qualitativo, procurando-se uma análise e compreensão das principais dinâmicas de vulnerabilização da classe média.

Previamente à seleção dos cidadãos de classe média a participar no estudo, adotou-se, com base numa significativa revisão de literatura de autores clássicos e contemporâneos, uma definição do conceito de classe média, sendo possível, a partir daí, estabelecer os critérios de seleção dos entrevistados.

Foram validadas vinte entrevistas, visando compreender as manifestações de vulnerabilidade económica e social na vida laboral/ atividade económica; vida familiar e estilo de vida e fruição cultural. Não tendo sido fixado desde o início um número de entrevistados adotaram-se os princípios da variação máxima ou heterogeneidade do ponto de vista da diferenciação no interior da classe social e dos acontecimentos cruciais desencadeadores da situação de vulnerabilização. Complementarmente, no decurso da pesquisa de campo, adotou-se o princípio da saturação (Guerra, 2006).

\section{Breve Enquadramento Conceptual: Crise Económico-social e Desqualificação Social}

A crise económica em Portugal teve início numa crise financeira e imobiliária, que posteriormente se refletiu no sistema económico, social e político (Marques e Matos, 2016). Multiplicaram-se os empregos instáveis, cresceu de forma abrupta o desemprego de longa duração, uma elevada precariedade laboral e, de novo, uma elevada emigração por motivos económicos. Estes fenómenos traduziram-se no aumento das desigualdades, espelhando uma sociedade enfrentando sérios problemas de coesão social, onde o emprego precário ronda os 30\% do emprego total em Portugal (Estanque, 2012, p. 69). 
Neste contexto, face à crise económica que atingiu todas as classes sociais da sociedade portuguesa e que deu origem a inúmeras situações de fragilidade e de rutura, torna-se fundamental analisar como é que a classe média portuguesa vem lidando com uma maior escassez de recursos, ou assegura a satisfação das suas necessidades fundamentais e garantir uma vida digna.

O conceito de "novos pobres" foi introduzido na linguagem das Ciências Sociais nas décadas de 80 e 90 com a emergência de novas vulnerabilidades sociais. Contextualizando, a década de 1980 ficou marcada pelo aparecimento de desemprego estrutural em vários países europeus. O fenómeno da precarização do trabalho, dada a sua ampla expressão, foi visto de modo igualmente importante ao do desemprego, uma vez que ambos conduzem com frequência a processos de destabilização e ao aparecimento de novas vulnerabilidades sociais. Como reflexo, verificou-se não só o aumento do número de desempregados, mas também de desemprego de longa duração, tendo sido neste contexto que se cria e regista o conceito de nova pobreza.

Ao se verificar a procura de serviços de ação social por novos grupos sociais, emerge 0 debate e a conceptualização da nova pobreza. Dito de outro modo, compreendeu-se que as origens da pobreza não poderiam ser todas justificadas pelas mesmas causas, mostrando-se a necessidade de compreender o surgimento de novas formas de pobreza diferenciadas.

Serge Paugam, refere que este fenómeno resulta de um conjunto de evoluções coincidentes, designadamente a precarização do mercado de trabalho, a instabilidade laboral e o desemprego de longa duração. O autor esclarece que a "desqualificação social" é também explicada pelo enfraquecimento dos laços sociais, gerando situações de isolamento e de vulnerabilidade. Argumenta que este processo provoca instabilidade familiar e quebra nos processos de solidariedade entre classes, sustentando que a deterioração do mercado de trabalho e o aumento do desemprego de longa duração afeta quer os jovens sem experiência profissional, quer os trabalhadores mais velhos.

O conceito de Serge Paugam sobre a desqualificação social teve como referência a experiência europeia do final da década de 80 , fazendo com que o conceito não possa ser transposto linearmente para a realidade e o fenómeno de crise económico-social atual. Deste modo, no contexto atual, procurámos entender como a precariedade económica e social conduzem à instabilidade do indivíduo, levando a uma fraca participação social e a processos de exclusão.

Em suma, pretendemos compreender qual a expressão, os contornos e as implicações que a repentina desqualificação social tem na vida dos cidadãos.

A perspetiva analítica adotada realça cinco eixos de análise: trabalho; família; saúde; relações sociais e bens materiais/estilo de vida. É a esta luz que importa analisar as narrativas dos cidadãos sob o prisma da hipótese da desqualificação social da classe média portuguesa.

\section{Metodologia}

A presente investigação apresenta uma natureza de cariz qualitativo, permitindo-se deste modo o recurso a um tratamento descritivo e interpretativo dos dados. Nesta lógica, adotase o ponto de vista de Bryman (1988) ao considerar que a análise qualitativa procura privilegiar o ponto de vista dos atores sociais, proporcionando uma maior descrição e focalização nos processos sociais, adotando técnicas flexíveis no desenvolvimento de conceitos e teorias. Neste sentido, a investigação qualitativa tem como objetivo compreender e interpretar os significados que os indivíduos e as sociedades atribuem aos diferentes fenómenos, procurando-se compreender as representações dos indivíduos (Denzin e Lincoln, 2000; 2006).

Nesta linha de análise, a nossa investigação focou-se no estudo de casos concretos, tendo sempre em conta as experiências e a opinião dos indivíduos (Flick, 2005), procurando-se interpretar os processos, significados e experiências dos cidadãos de classe média. 
Através da indução, descrição e interpretação, a abordagem qualitativa procede à descodificação dos discursos dos entrevistados. Por outras palavras, a realização de uma reflexão sobre as ações, observações, impressões e sentimentos, constituiu-se uma parte da interpretação dos dados (Flick, 2005). Essencialmente, a abordagem qualitativa procura compilar dados obtidos através das entrevistas (Flick, 2005), imperando a consciência de que esta abordagem envolve um trabalho de campo, onde o investigador é um sujeito ativo e interventor no estudo.

As entrevistas semiestruturadas despertam cada vez mais interesse e são crescentemente utilizadas em investigações pelo facto de os sujeitos poderem expressar com uma maior facilidade o seu ponto de vista, ao contrário das entrevistas estruturadas ou questionários (Flick, 2005). Contudo, a entrevista semiestruturada ou semidiretiva, não é na sua totalidade aberta, uma vez que está sujeita a linhas de orientação. Nesta lógica, no guião da entrevista estabelecem-se "temas guia" que vão sendo abordados no desenrolar da conversa (Pocinho, 2012).

Considerando a perspetiva de Blaikie (2009), a entrevista permite a interação dos atores sociais, propiciando-se uma maior proximidade, reproduzida na interpretação das atitudes e comportamentos dos entrevistados. Ao privilegiar-se o contacto direto, assume-se a intencionalidade da criação de uma relação de confiança ao longo do desenrolar das questões (Pocinho, 2012).

Nesta lógica, importa destacar que através das referências normativas dos cidadãos classe média, tornou-se possível uma reconstituição das suas ações, compreendendo-se os valores, os conflitos e experiências que deram e dão significado aos acontecimentos que ocorrem nas suas vidas (Pocinho, 2012).

A seleção dos cidadãos de classe média a entrevistar seguiu o critério de variação máxima da amostra, refletindo-se na integração de casos diferenciados, tendo em conta os seguintes aspetos: A possibilidade de os cidadãos de classe média poderem ser ou não, clientes de serviços de apoio e suporte social; Os cidadãos terem como requisito de escolaridade mínima o $12^{\circ}$ ano; Serem indivíduos com percursos de vida anteriormente marcados por estabilidade económica e integração social, experimentando no presente e passado recente, processos de vulnerabilização económica e social e desqualificação social.

Existiu um extenso processo de recrutamento para a seleção dos entrevistados, que envolveu variadas estratégias e negociação. No processo de recrutamento de entrevistados recorreu-se igualmente ao recrutamento por "bola de neve" através da indicação pelos próprios entrevistados de outros cidadãos em situação elegível para o estudo.

Ao assumirmos uma abordagem qualitativa, a representatividade estatística da amostra não se apresentava como um requisito, pelo que se procurou sobretudo realizar entrevistas com o máximo de heterogeneidade, garantindo deste modo que a investigação abordasse a maior variedade de situações.

O número definitivo de entrevistas foi de vinte cidadãos (16 mulheres e 4 homens), tendo as entrevistas tido uma duração variável entre 30 a 90 minutos.

A este respeito, gostaríamos ainda de evidenciar a dificuldade de recrutamento de participantes na investigação. É a esta luz que se revela significativo o conceito de "pobres envergonhados" de Castel, na medida em que, por diversas vezes, nos foi referido, através de contactos privilegiados, a recusa de participação dos possíveis candidatos, por estigma e sentimentos de vergonha.

No início das entrevistas, foi apresentado a todos os entrevistados um consentimento informado solicitando-se a autorização da gravação áudio, realçando-se a confidencialidade e a garantia que a sua identidade não seria revelada nem utilizada em nenhum contexto. 
Foi igualmente esclarecido que a qualquer momento a entrevista podia ser interrompida por decisão do entrevistado. As gravações áudio foram autorizadas em todas as entrevistas, sendo o período temporal da realização do estudo entre 2016 a 2019.

Morse (1998) refere que um bom "informante" deverá ter conhecimentos e noções do objetivo da entrevista, sendo essencial uma boa capacidade de análise, reflexão e discussão das temáticas que Ihe são perguntadas. Essa condição proporcionará uma entrevista mais profunda e ampliada. Nessa linha de argumentação, o facto de os entrevistados terem níveis de literacia elevados e facilidade em se expressarem, permitiu que as entrevistas fossem compreensíveis e distintas pelo grau de reflexibilidade.

O guião da entrevista foi organizado em três eixos de análise:

1. Percurso biográfica antes da crise

\section{Acontecimento crucial (Turning point)}

\section{Manifestações de vulnerabilidade e sofrimento}

Complementarmente foram recolhidos igualmente dados gerais de carácter sociodemográfico.

De acordo com Coutinho (2011) a quantidade de informação prestada pela abordagem qualitativa, implica necessariamente a sua organização e simplificação, de modo a que seja possível uma correta interpretação dos dados. Deste modo, a codificação permite compreender quais as categorias de análise, procurando-se selecionar temas chaves relevantes.

Flick (2005) refere que a codificação e a categorização é a essência da investigação qualitativa, considerando que este processo é o criador de teorias, sendo para isso imperioso, a associação de conceitos e relações entre as diferentes categorias.

Nesta sequência, e como resultado do aumento de investigações qualitativas nas últimas décadas, verificou-se o desenvolvimento de softwares para a análise de conteúdo. Entre os vários programas, destaca-se o software MAXQDA para a análise de dados qualitativos. A utilização deste programa permitiu-nos uma análise das regularidades, variações e singularidades dos dados analisados.

Nesta lógica sublinha-se igualmente o ponto de vista do autor ao referir que a utilização de programas QDA aumentam a validação da investigação, já que existe uma maior transparência entre orientado e orientador, na análise dos dados e na codificação dos segmentos e das suas interpretações.

Neste contexto, a partir da análise das entrevistas, realizámos um sistema de classificação de diferentes categorias (acontecimentos, eventos, fenómenos, sentimentos), que de seguida associamos a subcategorias relacionando-as aos objetivos específicos da nossa investigação.

Como ponto de partida, foi realizado uma codificação aberta, num processo moroso e aperfeiçoado pela análise e comparação das diferentes entrevistas. Se inicialmente se identificaram numerosos códigos, através do seu agrupamento por proximidade de conteúdo e relevância analítica (codificação seletiva) foi possível o estabelecimento das categorias finais. Nesse sentido, ao longo do processo de codificação foram realizadas anotações com o objetivo de esclarecer e definir as diferentes categorias, para definir mais precisamente o conteúdo da categoria (Flick, 2005, p. 181). 
Tabela 1. Sistema de códigos Classe Média (MaxQda 2018)

\begin{tabular}{|c|c|}
\hline Códigos & Subcódigos: \\
\hline Condição Social de Vida Antes da Crise & $\begin{array}{l}\text { Posição Social enquanto Classe Média } \\
\text { Condição Perante Trabalho/Profissão }\end{array}$ \\
\hline $\begin{array}{l}\text { Turning Point: Acontecimento crucial que levou } \\
\text { a dinâmicas de vulnerabilização }\end{array}$ & $\begin{array}{l}\text { Compra de empresa/ negócio fraudulento } \\
\text { Encerramento de negócio } \\
\text { Endividamento pelo cônjuge/ companheiro } \\
\text { Divórcio } \\
\text { Despedimento e/ou desemprego } \\
\text { Encerramento de empresa por falecimento do } \\
\text { empregador } \\
\text { Problemas de gestão e adaptação empresarial } \\
\text { Crise indústria, têxtil e imobiliária } \\
\text { Cortes salariais na administração pública } \\
\text { Impossibilidade cumprir obrigações crédito honrando } \\
\text { compromisso }\end{array}$ \\
\hline $\begin{array}{l}\text { Manifestações de vulnerabilidade económica e } \\
\text { social }\end{array}$ & $\begin{array}{l}\text { Perda de Património } \\
\text { Perda da guarda do filho por insuf. económica } \\
\text { Precarização das condições de trabalho com redução } \\
\text { rendimentos } \\
\text { Impossibilidade de realizar poupança } \\
\text { Falta de apoio financeiro por ex-conjuge } \\
\text { Alteração padrões consumo } \\
\text { Impactos na situação residencial / habitação } \\
\text { Impactos na vida familiar (conjugal, filhos, pais) } \\
\text { Impactos vida social }\end{array}$ \\
\hline
\end{tabular}

Os cidadãos de classe média apresentam trajetórias de vulnerabilização com aspetos convergentes e divergentes. O contexto, mas também a história pessoal, familiar e profissional, influenciam as diferentes dinâmicas de vulnerabilização, e, por conseguinte, as estratégias de enfrentamento da situação.

Neste sentido, através da análise das diferentes entrevistas, construímos esquemas biográficos que não só apresentam o perfil de cada cidadão de classe média entrevistado, como uma síntese dos discursos que contêm a mensagem essencial da entrevista (Guerra, 2006, p. 73), identificados em diferentes períodos temporais. A construção de esquemas biográficos permitiu-nos não só analisar a heterogeneidade das entrevistas efetuadas, amostragem esta diversificada e refletida em testemunhos inéditos e de relevância, bem como a possibilidade de percecionar o ponto de saturação das entrevistas quando os dados que estão a ser recolhidos não trazem mais informações novas ou diferentes que justifiquem um aumento da recolha de material empírico (Guerra, 2006, p. 42). 
Tabela 2. Exemplo de esquema biográfico dos cidadãos de classe mé

\begin{tabular}{|c|c|c|c|c|}
\hline CM19 & $\begin{array}{l}\text { Atividade } \\
\text { Económica/Profissional }\end{array}$ & $\begin{array}{l}\text { Vida } \\
\text { Familiar/Pessoal }\end{array}$ & $\begin{array}{l}\text { Trajetória } \\
\text { Residencial }\end{array}$ & $\begin{array}{l}\text { Recurso } \\
\text { Serviços } \\
\text { Sociais }\end{array}$ \\
\hline Perfil & $\begin{array}{l}46 \text { anos, licenciada em } \\
\text { Sociologia }\end{array}$ & & & \\
\hline Ante & $\begin{array}{l}\text { Empresa familiar (pais e } \\
\text { irmãos) }\end{array}$ & $\begin{array}{l}\text { Casada, com dois } \\
\text { filhos }\end{array}$ & Casa própria & \\
\hline $\begin{array}{l}\text { Incidente } \\
\text { Crítico / } \\
\text { "Turning } \\
\text { Point" }\end{array}$ & $\begin{array}{l}\text { Falência empresa familiar } \\
\text { (Quebra de vendas e clientes) }\end{array}$ & $\begin{array}{l}\text { Falência negócio do } \\
\text { cônjuge e } \\
\text { consequente } \\
\text { divórcio }\end{array}$ & $\begin{array}{l}\text { Venda da } \\
\text { casa } \\
\text { (Com o } \\
\text { divórcio, C19 } \\
\text { sai de casa } \\
\text { com os filhos) }\end{array}$ & \\
\hline Pós & $\begin{array}{l}\text { - Desempregada } \\
\text { - Medida CEI } \\
\text { - Novamente desempregada } \\
\text { (subsídio desemprego) }\end{array}$ & & Casa alugada & $\begin{array}{l}\text { Abono } \\
\text { RSI } \\
\text { Cabaz } \\
\text { social }\end{array}$ \\
\hline Perspetivas & $\begin{array}{l}\text { Procura de emprego na área } \\
\text { da sociologia }\end{array}$ & & & \\
\hline
\end{tabular}

\section{Resultados}

Os dados recolhidos indiciam que estamos perante cidadãos que se afastam dos atributos apontados pela literatura à classe média, em consequência das trajetórias de mobilidade social descendente ou mobilidade ascensional estagnada provocadas pelos processos de vulnerabilização económica e social a que foram submetidos.

Neste contexto, a esfera do trabalho emerge como uma das principais dimensões deste estudo, refletindo a fragilidade das condições de trabalho por via de processos de precarização, instabilidade e subsequente não empregabilidade dos qualificados (Castel, 1998, p. 521). Neste contexto, face ao desemprego e/ou não trabalho, como alternativa ao emprego de recorte mais clássico, o empreendedorismo e a criação do próprio emprego, configuram-se em vários casos como novas formas de precarização de trabalho, com vencimentos baixos e inexistência de um conjunto de direitos como férias, subsídios e descanso semanal.

Igualmente, um dos resultados mais significativos traduz-se em processos de desqualificação profissional de cidadãos que apesar de se encontrarem inseridos no mercado de trabalho, não se encontram a trabalhar na área de formação e/ou especialização e/ou têm vínculos contratuais caracterizados pela precariedade.

Desde que me divorciei, estive a trabalhar num restaurante a lavar pratos depois do trabalho.

$$
\text { C10, } 12^{\circ} \text { ano, empregada. }
$$

Em relação ao eixo da vida familiar, observam-se neste âmbito, indicadores de processos de desqualificação social. No presente estudo registam-se situações em que se verifica falta de apoio financeiro para a criação dos filhos face a situações de divórcio.

Registam-se casos de cidadãos em que os seus relacionamentos familiares e afetivos apresentam sinais claros de deterioração face às dinâmicas de vulnerabilização económica e social, e em que em alguns casos se instalou não só a desconfiança entre cônjuges, como ocorreram mesmo situações de violência conjugal e doméstica. 
Num sentido diferente, do ponto de vista do recurso à solidariedade familiar, constata-se, tendo por base os resultados do presente estudo, que os cidadãos de classe média recorrem em primeira instância às suas famílias para apoio e satisfação de encargos e responsabilidades. Estes resultados colocam em evidência que uma grande parte dos cidadãos não recorre aos serviços de apoio e ação social, mobilizando preferencialmente o apoio e solidariedade familiar.

De uma maneira geral, os dados recolhidos permitiram identificar que a saúde, como dimensão de bem-estar físico e mental, quando em risco, afeta de forma clara a componente social. Da mesma forma, importa salientar o impacto que a precariedade social tem no estado de saúde dos indivíduos. Podemos assim dizer que ambas as dimensões se influenciam. Doenças incapacitantes, problemas emocionais, ansiedade, depressão e a perda de autoestima, poderão ser antecedentes de tentativas de suicídio, muitas vezes associadas a processos de desqualificação social.

Nesta linha, o nosso estudo evidencia ainda a deterioração das redes sociais, que surge relacionada com a insuficiência económica, associada a uma retração do contacto e sociabilidade quer por autoisolamento, quer pela impossibilidade em acompanhar os estilos de vida das pessoas que não experimentaram os mesmos processos de vulnerabilização económica e social. Sendo nas relações sociais que se encontra a base de convivência fundamental de qualquer cidadão, a sua deterioração potencia também a diminuição do acesso à cultura e a participação na vida da comunidade, constituindo-se como um indicador crítico de retração da vida social de cidadãos envolvidos em processos de vulnerabilização económica e social.

Por último, as alterações na esfera dos bens materiais/ estilos de vida ocupam uma parte significativa nas narrativas dos entrevistados, já que se traduzem nas aspirações, gostos, comportamentos e estilos de vida associados à classe média. Ser proprietário de uma casa é uma das principais aspirações que compõe o estilo de vida da classe média. Contudo, a presente investigação constatou que a maioria dos entrevistados apresenta alterações na sua situação residencial, evidenciando-se casos de transição para casas mais económicas, casas/anexos emprestados por familiares e o regresso à casa dos pais, numa dinâmica de retração e retrocesso dos seus projetos de vida. Esta conclusão está em linha com a análise da OCDE (2019), cujo relatório revela que a habitação em Portugal, Espanha e Irlanda, contribuiu para a precarização de forma particularmente acentuada de cidadãos de classe média.

Tendo por base a análise detalhada das trajetórias referentes à carreira ocupacional, vida pessoal e situação residencial, sistematiza-se, na tabela 3 , de forma integrada, os impactos e consequências observadas nestas dimensões na história de vida de cada entrevistado, numa primeira aproximação ao impacto registado em termos de mobilidade social destes cidadãos da classe média. 
Tabela 3. Impactos da vulnerabilização económica e social nas trajetórias ocupacional, familiar e residencial dos cidadãos da classe média

\begin{tabular}{|c|c|c|c|}
\hline & Percurso Ocupacional & Percurso Vida Familiar & Percurso Residencial \\
\hline $\mathrm{C} 1$ & Reforma $\rightarrow$ & NA & Sem alteração residência $\rightarrow$ \\
\hline $\mathrm{C} 2$ & Desemprego $\downarrow$ & Sem alteração $\rightarrow$ & Retorno casa de família \\
\hline $\mathrm{C} 3$ & Empreendedorismo & Sem alteração $\rightarrow$ & $\begin{array}{l}\text { Mudança habitação menor ou } \\
\text { mais económica } \downarrow\end{array}$ \\
\hline $\mathrm{C} 4$ & Empreendedorismo & $\begin{array}{l}\text { Deterioração relação conjugal } \\
\downarrow\end{array}$ & Sem alteração residência $\rightarrow$ \\
\hline C5 & Empreendedorismo & Divórcio ou separação $\downarrow$ & $\begin{array}{l}\text { Mudança habitação menor ou } \\
\text { mais económica } \downarrow\end{array}$ \\
\hline C6 & Reforma $\downarrow$ & Sem alteração $\rightarrow$ & Retorno casa de família \\
\hline $\mathrm{C7}$ & Desemprego $\downarrow$ & Sem alteração $\rightarrow$ & $\begin{array}{l}\text { Mudança habitação menor ou } \\
\text { mais económica } \downarrow\end{array}$ \\
\hline $\mathrm{C} 8$ & Desemprego $\downarrow$ & Divórcio ou separação $\downarrow$ & Retorno casa de família \\
\hline C9 & Desemprego $\downarrow$ & Divórcio ou separação $\downarrow$ & Retorno casa de família \\
\hline C10 & $\begin{array}{l}\text { Desqualificação } \\
\text { profissional / } \\
\text { Precariedade } \downarrow\end{array}$ & Sem alteração $\rightarrow$ & $\begin{array}{l}\text { Mudança habitação menor ou } \\
\text { mais económica } \downarrow\end{array}$ \\
\hline C11 & Empreendedorismo & $\begin{array}{l}\text { Deterioração relação conjugal } \\
\downarrow\end{array}$ & Sem alteração residência $\rightarrow$ \\
\hline C12 & $\begin{array}{l}\text { Desqualificação } \\
\text { profissional / } \\
\text { Precariedade } \downarrow\end{array}$ & NA & Sem alteração residência $\rightarrow$ \\
\hline C13 & Desemprego $\downarrow$ & $\begin{array}{l}\text { Deterioração relação conjugal } \\
\downarrow\end{array}$ & Sem alteração residência $\rightarrow$ \\
\hline C14 & $\begin{array}{l}\text { Desqualificação } \\
\text { profissional// } \\
\text { Precariedade } \downarrow\end{array}$ & Sem alteração $\rightarrow$ & Retorno casa de família \\
\hline C15 & $\begin{array}{l}\text { Desqualificação } \\
\text { profissional / } \downarrow \\
\text { Precariedade }\end{array}$ & Sem alteração $\rightarrow$ & $\begin{array}{l}\text { Mudança habitação menor ou } \\
\text { mais económica } \downarrow\end{array}$ \\
\hline C16 & $\begin{array}{l}\text { Desqualificação } \\
\text { profissional / } \\
\text { Precariedade } \downarrow\end{array}$ & Sem alteração $\rightarrow$ & $\begin{array}{l}\text { Mudança habitação menor ou } \\
\text { mais económica } \downarrow\end{array}$ \\
\hline C17 & Empreendedorismo & Sem alteração $\rightarrow$ & Retorno casa de família $\downarrow$ \\
\hline C18 & $\begin{array}{l}\text { Desqualificação } \\
\text { profissional / } \downarrow \\
\text { Precariedade }\end{array}$ & Sem alteração $\rightarrow$ & $\begin{array}{l}\text { Mudança habitação menor ou } \\
\text { mais económica } \downarrow\end{array}$ \\
\hline C19 & Desemprego $\downarrow$ & Divórcio ou separação $\downarrow$ & $\begin{array}{l}\text { Mudança habitação menor ou } \\
\text { mais económica } \downarrow\end{array}$ \\
\hline C20 & Desemprego $\downarrow$ & Sem alteração $\rightarrow$ & Retorno casa de família \\
\hline
\end{tabular}

Explorando outras dimensões de análise dos bens materiais, a precarização socioeconómica das famílias de classe média, em muitos casos, manifesta-se na impossibilidade de proporcionar aos filhos o estilo de vida desejado, designadamente no âmbito da educação e instrução. Confirmam-se alterações significativas no padrão de vida dos seus filhos, ao nível de privação/restrição de bens de consumo, ensino e aquisição de bens materiais. Esta dimensão, como é aludido no relatório da OCDE (2019), ao afetar as condições de sucesso e progresso escolar dos jovens compromete a mobilidade social ascendente, traduzindo-se na redução das taxas de participação da educação infantil, como também no desencorajamento dos jovens de ingressarem no ensino superior. 
Os dados recolhidos permitiram identificar que as situações de privação material se intensificam no caso das mulheres, já que tradicionalmente são as principais provedoras dos cuidados aos progenitores.

Outra tensão observada prende-se com a necessidade de os cidadãos abdicarem das férias como estratégia de contenção de gastos e de enfrentamento da quebra de rendimentos. Concretamente, e tendo como referência o indicador de privação material, a não concretização de férias uma vez por ano fora de casa, é um dos items representativos. A evidência recolhida aponta claramente como uma das estratégias de enfrentamento da precariedade económica a redução dos períodos de férias, a procura de programas de férias menos dispendiosos e próximas de casa, como o recurso a oportunidades proporcionadas por familiares e amigos.

\section{Posso dizer que não fazemos viagens desde 2010. Que foi que penso que foi o ponto alto da crise económica. Deixamos de fazer férias porque a partir do momento em que uma pessoa tem outras prioridades, nomeadamente dar acesso ao ensino aos filhos.}

C12, mestrado, empregada.

Outro aspeto a destacar, no que respeita às práticas de consumo, é a necessidade sublinhada pelos entrevistados de poupança e de controlo dos seus gastos e despesas. Neste plano os discursos acentuam uma restrição no recurso à restauração e a opção por refeições confecionadas em casa como estratégia de poupança. Nesta linha de argumentação, o estudo evidencia que os consumidores portugueses seguem cada vez mais a tendência de aquisição de marcas de distribuidor em detrimento das marcas de fabricante. Foi igualmente verificado o acesso a bens e serviços low-cost, ainda que, na sua base se possam encontrar aspetos comuns com os serviços utilizados antes do processo de precarização.

Neste contexto, de forma a ensaiar uma análise mais fina da alteração dos padrões de consumo dos cidadãos da classe média abrangidos pelo estudo, e suas famílias, construiu-se, por analogia ao indicador "taxa de privação material" utilizado pelo Eurostat - no âmbito do SILC, um indicador da alteração do padrão de consumo na sequência dos processos de vulnerabilização económica e social que afetaram os cidadãos entrevistados. Quando os indivíduos residentes em agregados familiares não tem acesso a pelo menos três (3) dos itens que compõem aquele indicador, definiu-se como:

Alteração Ligeira: não acesso a um item;

Alteração Moderada: não acesso a dois itens;

Alteração Severa: não acesso a três ou mais itens.

Assim, como revela a tabela 4, os nossos resultados evidenciam que de acordo com este indicador, a maioria dos cidadãos da classe média abrangida pelo estudo sofreu uma alteração severa nos seus padrões de consumo, registando alterações em toda a amostra.

Note-se, no entanto, que a não alusão no guião da entrevista a questões específicas relacionadas com as categorias apresentadas, leva a que reconheçamos a possibilidade de outros cidadãos entrevistados terem igualmente experimentado essas alterações. Contudo, nesta análise foram apenas consideradas as alterações explicitamente mencionadas pelos entrevistados. 
Tabela 4. Alterações no padrão de consumo dos cidadãos de Classe Média

\begin{tabular}{|c|c|c|c|c|c|c|c|c|}
\hline $\mathbf{E}$ & $\begin{array}{l}\text { Alteração } \\
\text { padrão de } \\
\text { vida dos } \\
\text { filhos }\end{array}$ & $\begin{array}{l}\text { Alteração } \\
\text { no acesso à } \\
\text { cultura }\end{array}$ & $\begin{array}{l}\text { Alterações } \\
\text { no padrão } \\
\text { de férias }\end{array}$ & $\begin{array}{l}\text { Utilização } \\
\text { automóvel }\end{array}$ & $\begin{array}{l}\text { Restrição do } \\
\text { recurso à } \\
\text { restauração }\end{array}$ & $\begin{array}{l}\text { Aquisição de } \\
\text { bens low } \\
\text { cost }\end{array}$ & $\begin{array}{l}\text { Outras } \\
\text { alterações } \\
\text { padrões } \\
\text { consumo }\end{array}$ & $\begin{array}{l}\text { Indicador } \\
\text { alteração } \\
\text { padrão de } \\
\text { consumo }\end{array}$ \\
\hline C1 & N.A. & $\begin{array}{l}\text { Não } \\
\text { menciona }\end{array}$ & Menciona & $\begin{array}{l}\text { Não } \\
\text { menciona }\end{array}$ & Menciona & $\begin{array}{l}\text { Não } \\
\text { menciona }\end{array}$ & $\begin{array}{l}\text { Não } \\
\text { menciona }\end{array}$ & $\begin{array}{l}\text { Alteração } \\
\text { Moderada }\end{array}$ \\
\hline $\mathrm{C} 2$ & Menciona & $\begin{array}{l}\text { Não } \\
\text { menciona }\end{array}$ & $\begin{array}{l}\text { Não } \\
\text { menciona }\end{array}$ & $\begin{array}{l}\text { Não } \\
\text { menciona }\end{array}$ & $\begin{array}{l}\text { Menciona Apoio } \\
\text { Alimentar ... }\end{array}$ & $\begin{array}{l}\text { Menciona } \\
\text { Apoio } \\
\text { Alimentar ... }\end{array}$ & $\begin{array}{l}\text { Não } \\
\text { menciona }\end{array}$ & $\begin{array}{l}\text { Alteração } \\
\text { Severa }\end{array}$ \\
\hline C3 & N.A. & $\begin{array}{l}\text { Não } \\
\text { menciona }\end{array}$ & Menciona & Menciona & Não menciona & $\begin{array}{l}\text { Não } \\
\text { menciona }\end{array}$ & $\begin{array}{l}\text { Não } \\
\text { menciona }\end{array}$ & $\begin{array}{l}\text { Alteração } \\
\text { Moderada }\end{array}$ \\
\hline C4 & Menciona & $\begin{array}{l}\text { Não } \\
\text { menciona }\end{array}$ & Menciona & $\begin{array}{l}\text { Não } \\
\text { menciona }\end{array}$ & Não menciona & $\begin{array}{l}\text { Não } \\
\text { menciona }\end{array}$ & $\begin{array}{l}\text { Não } \\
\text { menciona }\end{array}$ & $\begin{array}{l}\text { Alteração } \\
\text { Moderada }\end{array}$ \\
\hline C5 & N.A. & $\begin{array}{l}\text { Não } \\
\text { menciona }\end{array}$ & Menciona & $\begin{array}{l}\text { Não } \\
\text { menciona }\end{array}$ & Menciona & $\begin{array}{l}\text { Não } \\
\text { menciona }\end{array}$ & $\begin{array}{l}\text { Não } \\
\text { menciona }\end{array}$ & $\begin{array}{l}\text { Alteração } \\
\text { Moderada }\end{array}$ \\
\hline C6 & $\begin{array}{l}\text { Não } \\
\text { menciona }\end{array}$ & Menciona & Menciona & $\begin{array}{l}\text { Não } \\
\text { menciona }\end{array}$ & Menciona & $\begin{array}{l}\text { Não } \\
\text { menciona }\end{array}$ & $\begin{array}{l}\text { Não } \\
\text { menciona }\end{array}$ & $\begin{array}{l}\text { Alteração } \\
\text { Severa }\end{array}$ \\
\hline C7 & Menciona & Menciona & Menciona & Menciona & Menciona & $\begin{array}{l}\text { Não } \\
\text { menciona }\end{array}$ & Menciona & $\begin{array}{l}\text { Alteração } \\
\text { Severa }\end{array}$ \\
\hline C8 & Menciona & $\begin{array}{l}\text { Não } \\
\text { menciona }\end{array}$ & Menciona & $\begin{array}{l}\text { Não } \\
\text { menciona }\end{array}$ & Menciona & Menciona & $\begin{array}{l}\text { Não } \\
\text { menciona }\end{array}$ & $\begin{array}{l}\text { Alteração } \\
\text { Severa }\end{array}$ \\
\hline C9 & N.A. & $\begin{array}{l}\text { Não } \\
\text { menciona }\end{array}$ & Menciona & $\begin{array}{l}\text { Não } \\
\text { menciona }\end{array}$ & Menciona & Menciona & $\begin{array}{l}\text { Não } \\
\text { menciona }\end{array}$ & $\begin{array}{l}\text { Alteração } \\
\text { Severa }\end{array}$ \\
\hline C10 & Menciona & Menciona & Menciona & $\begin{array}{l}\text { Não } \\
\text { menciona }\end{array}$ & $\begin{array}{l}\text { Menciona Apoio } \\
\text { Alimentar ... }\end{array}$ & Menciona & Menciona & $\begin{array}{l}\text { Alteração } \\
\text { Severa }\end{array}$ \\
\hline C11 & Menciona & $\begin{array}{l}\text { Não } \\
\text { menciona }\end{array}$ & $\begin{array}{l}\text { Não } \\
\text { menciona }\end{array}$ & $\begin{array}{l}\text { Não } \\
\text { menciona }\end{array}$ & $\begin{array}{l}\text { Menciona Apoio } \\
\text { Alimentar ... }\end{array}$ & $\begin{array}{l}\text { Menciona } \\
\text { Apoio } \\
\text { Alimentar ... }\end{array}$ & $\begin{array}{l}\text { Não } \\
\text { menciona }\end{array}$ & $\begin{array}{l}\text { Alteração } \\
\text { Severa }\end{array}$ \\
\hline C12 & N.A. & Menciona & Menciona & Menciona & Não menciona & Menciona & $\begin{array}{l}\text { Não } \\
\text { menciona }\end{array}$ & $\begin{array}{l}\text { Alteração } \\
\text { Severa }\end{array}$ \\
\hline C13 & Menciona & $\begin{array}{l}\text { Não } \\
\text { menciona }\end{array}$ & Menciona & $\begin{array}{l}\text { Não } \\
\text { menciona }\end{array}$ & Menciona & $\begin{array}{l}\text { Não } \\
\text { menciona }\end{array}$ & $\begin{array}{l}\text { Não } \\
\text { menciona }\end{array}$ & $\begin{array}{l}\text { Alteração } \\
\text { Severa }\end{array}$ \\
\hline C14 & N.A. & Menciona & Menciona & $\begin{array}{l}\text { Não } \\
\text { menciona }\end{array}$ & Menciona & $\begin{array}{l}\text { Não } \\
\text { menciona }\end{array}$ & $\begin{array}{l}\text { Não } \\
\text { menciona }\end{array}$ & $\begin{array}{l}\text { Alteração } \\
\text { Severa }\end{array}$ \\
\hline C15 & Menciona & $\begin{array}{l}\text { Não } \\
\text { menciona }\end{array}$ & Menciona & $\begin{array}{l}\text { Não } \\
\text { menciona }\end{array}$ & Não menciona & $\begin{array}{l}\text { Não } \\
\text { menciona }\end{array}$ & $\begin{array}{l}\text { Não } \\
\text { menciona }\end{array}$ & $\begin{array}{l}\text { Alteração } \\
\text { Moderada }\end{array}$ \\
\hline C16 & Menciona & $\begin{array}{l}\text { Não } \\
\text { menciona }\end{array}$ & Menciona & Menciona & Não menciona & $\begin{array}{l}\text { Não } \\
\text { menciona }\end{array}$ & $\begin{array}{l}\text { Não } \\
\text { menciona }\end{array}$ & $\begin{array}{l}\text { Alteração } \\
\text { Severa }\end{array}$ \\
\hline C17 & N.A. & Menciona & $\begin{array}{l}\text { Não } \\
\text { menciona }\end{array}$ & $\begin{array}{l}\text { Não } \\
\text { menciona }\end{array}$ & Não menciona & $\begin{array}{l}\text { Menciona } \\
\text { Apoio } \\
\text { Alimentar ... }\end{array}$ & $\begin{array}{l}\text { Não } \\
\text { menciona }\end{array}$ & $\begin{array}{l}\text { Alteração } \\
\text { Moderada }\end{array}$ \\
\hline C18 & Menciona & Menciona & Menciona & $\begin{array}{l}\text { Não } \\
\text { menciona }\end{array}$ & Menciona & Menciona & $\begin{array}{l}\text { Não } \\
\text { menciona }\end{array}$ & $\begin{array}{l}\text { Alteração } \\
\text { Severa }\end{array}$ \\
\hline C19 & Menciona & Menciona & Menciona & Menciona & $\begin{array}{l}\text { Menciona Apoio } \\
\text { Alimentar ... }\end{array}$ & $\begin{array}{l}\text { Menciona } \\
\text { Apoio } \\
\text { Alimentar... }\end{array}$ & $\begin{array}{l}\text { Não } \\
\text { menciona }\end{array}$ & $\begin{array}{l}\text { Alteração } \\
\text { Severa }\end{array}$ \\
\hline $\mathrm{C2O}$ & Menciona & Menciona & $\begin{array}{l}\text { Não } \\
\text { menciona }\end{array}$ & $\begin{array}{l}\text { Não } \\
\text { menciona }\end{array}$ & $\begin{array}{l}\text { Menciona Apoio } \\
\text { Alimentar ... }\end{array}$ & $\begin{array}{l}\text { Não } \\
\text { menciona }\end{array}$ & $\begin{array}{l}\text { Não } \\
\text { menciona }\end{array}$ & $\begin{array}{l}\text { Alteração } \\
\text { Severa }\end{array}$ \\
\hline
\end{tabular}

\section{Conclusão}

Com o presente estudo procurou-se analisar os processos de vulnerabilização da classe média em Portugal, bem como a procura do serviço social e de estruturas de apoio e suporte social por este "novo e diferenciado público".

Os dados recolhidos indiciam que estamos perante cidadãos que se afastam dos atributos apontados pela literatura à classe média, em consequência das trajetórias de mobilidade social descendente ou mobilidade ascensional estagnada provocadas pelos processos de vulnerabilização económica e social a que foram submetidos. 
Através do desenvolvimento de uma investigação qualitativa, foi possível identificar diferentes processos de vulnerabilização económica e social de cidadãos da classe média, apurando-se o significado de perdas objetivas e subjetivas, decorrentes de fenómenos diferenciados como o desemprego, ruturas conjugais, precarização laboral, alterações dos estilos de vida, mobilidade social descendente e falta de perspetivas para o futuro.

O presente estudo apresenta limitações que convidam a uma postura cautelosa em algumas conclusões do mesmo. Em primeiro lugar, é uma investigação de carácter qualitativo de pequena escala, abrangendo apenas vinte cidadãos de classe média. Neste sentido, apesar de ter sido orientado pelo princípio da heterogeneidade, incluindo uma diversidade significativa de entrevistados, entende-se que os resultados não podem ser generalizáveis requerendo-se aprofundamento com base em desenhos de pesquisa empírica mais ampla, e dados atualizados da estrutura de classes em Portugal.

Apesar das limitações apontadas seria muito complexa a adoção de outra estratégia de investigação, já que se regista escassa investigação científica e bases de dados estatísticos sobre a classe média portuguesa.

Neste cenário, evidencia-se ainda a dificuldade de recrutamento de cidadãos de classe média através de assistentes sociais de diferentes serviços sociais, como a dificuldade dos públicos diferenciados recorrerem aos serviços de apoio e ação social, ou por sua iniciativa entenderem partilhar as suas experiências de vulnerabilização social.

Ainda que no presente estudo o observatório social considerado apresente limitações, a opção por um estudo qualitativo foi sustentada numa representatividade teórica significativa e que empiricamente veio a ser comprovada. Nesta ótica, no quadro da discussão sobre o estudos de caso em Ciências Sociais como refere Branco (2001, p. 15),

\section{[...]o que está sobretudo em causa são as qualidades reconhecidas ao caso seleccionado para ilustrar o problema em estudo e que lhe permitem atribuir representatividade teórica. A explicitação das qualidades do caso como ponto de observação ideal são, nesta perspectiva, um requisito de fundamental importância.}

Estas questões não colocam em causa, no entanto, o que de mais importante sobressai deste trabalho. Ao justificar a necessidade de refletir sobre a "nova questão social", Castel (1998, p. 528) alertava para a desestabilização dos estáveis e sequente bloqueio da mobilidade social ascendente de determinados grupos sociais, prevendo a precariedade como destino.

O período em que decorreu a crise económica em Portugal e as políticas de austeridade, não afetaram somente as populações mais vulneráveis, dando também origem ao surgimento de casos de "nova pobreza", casos estes nada correspondentes aos da pobreza tradicional, como ocorreu com inúmeros cidadãos da classe média.

Foi o propósito de dar visibilidade a este fenómeno e contribuir para o seu estudo que esteve na base do presente estudo.

\section{Referências}

Branco, F. (2001). A face lunar dos direitos sociais - virtualidades e limites do RMG como direito de cidadania em Portugal. (Tese de Doutoramento), Pontifícia Universidade Católica de São Paulo

Bryman, A. (1988). Quality and Quantity in Social Research. London: Unwin Hyman

Castel, R. (1998). As metamorfoses da questão social: Uma crónica do salário. Petrópolis: Editora Vozes

Castel, R. (2000). A precaridade: transformações históricas e tratamento social. In M.-H. Soulet (Ed.), Da não-integração. Coimbra: Quarteto

Coutinho, C. P. (2011). Metodologias de Investigação em Ciências Sociais e Humanas: Teoria e Prática. Coimbra: Almedina.978-972-40-4487-3 
Denzin, N. K. e Lincoln, Y. S. (2000). Handbook of qualitative research. Thousand Oaks: Sage Publications

Denzin, N. K. e Lincoln, Y. S. (2006). O planejamento da pesquisa qualitativa: teorias e abordagens. Porto Alegre: Artmed

Estanque, E. (2012). A Classe Média: Ascensão e Declínio. Lisboa: Fundação Francisco Manuel dos Santos

Flick, U. (2005). Métodos Qualitativos na Investigação Científica. Lisboa: Monitor

Guerra, I. C. (2006). Pesquisa Qualitativa e Análise de Conteúdo - Sentidos e formas de uso. Estoril: Princípia

Marques, T. S. e Matos, F. L. d. (2016). Crise e vulnerabilidade social: uma leitura territorial. In L. Lourenço (Ed.), Geografia, Paisagem e Riscos. Coimbra: Imprensa da Universidade de Coimbra

Morse, J. (1998). Designing Funded Qualitative Research. In Y. L. N. Denzin (Ed.), Strategies of Qualitative Inquiry (pp. 56-85). Thousand Oaks, CA: Sage Publication

OECD. (2019). Under Pressure: The Squeezed Middle Class. Retrieved from Paris: https://doi.org/10.1787/689afed1-en

Paugam, S. (1991/2003). A Desqualificação Social: Ensaio sobre a nova pobreza Porto Porto Editora

Paugam, S. (1993). La Societe Francaise Et Ses Pauvres. Paris: Quadrige

Paugam, S. (1999). O Enfraquecimento e a Ruptura dos Vínculos Sociais - uma dimensão essencial do processo de desqualificação social. In B. Sawaia (Ed.), As Artimanhas da Exclusão: Análise Psicossocial e Ética da Desigualdade Social (2a ed., pp. 67-86). Petrópolis: Editora Vozes

Paugam, S. (2000). A desqualificação social. In M.-H. Soulet (Ed.), Da não-integração. Coimbra: Quarteto

Paugam, S. (2007). Las formas elementales de la pobreza. Madrid: Alianza Editorial

Pocinho, M. (2012). Metodologia de Investigação e Comunicação do Conhecimento Científico. Lisboa: Lidel. 